\section{Nueva forma de adquirir la especialidad en Medicina Interna, en Polonia}

\section{New pathway to obtain a specialty in Internal Medicine, in Poland}

\section{Sr. Editor:}

En Polonia los estudios de medicina duran 6 años ${ }^{1}$. Para matricularse en la carrera hay que dar un examen de biología, química, matemática o física, en su escuela secundaria. Durante los estudios de medicina hay que rendir muchos exámenes y a partir del tercer curso algunos incluyen temas de medicina interna. El examen general de medicina interna se debe dar en el último curso e incluye tres partes: oral, escrita y práctica, y deben aprobarse las tres ${ }^{1}$. Muchos estudiantes lo describen como el examen más difícil durante sus estudios. Siempre la parte oral contiene preguntas sobre cardiología y farmacología.

Una vez aprobados estos exámenes, hay que iniciar una práctica obligatoria de 13 meses, rotando por muchas secciones. No se toma en cuenta la intención de dedicarse a una especialidad determinada, como ginecología, oftalmología, pediatría, etc. ${ }^{3}$ La rotación más larga (10 semanas) se hace en medicina interna. Cada médico cumple y registra sus actividades (tiene su libro de práctica) y recoge las firmas de los médicos que fueron tutores durante su rotación, certificando que ha cumplido sus deberes y ha aprendido las competencias requeridas.

Terminados los 13 meses de práctica, hay que aprobar un examen nacional, que contiene 200 preguntas escritas (39 son de medicina interna, $20 \%$ ), que se deben responder en $4 \mathrm{~h}$. El examen se puede rendir en dos fechas anuales: febrero y septiembre 2 . Para aprobarlo se requiere un mínimo de $56 \%$ de respuestas correctas.

Al terminar la práctica de 13 meses y aprobar el examen nacional, se obtiene el título de médico y puede ejercer como médico privado, pero no en instituciones.

Una vez aprobado este examen (que en Polonia se llama LEK) el médico debe elegir su especialidad entre aquellos cupos dados por el Ministerio de Salud, lo que se ofrece cada febrero y septiembre ${ }^{6}$. Para postular se requiere el diploma de estudios rendidos y aprobados, el resultado del examen LEK, la solicitud de hospital y especialidad elegidos. Este trámite se puede hacer por internet ${ }^{4}$.

\section{Medicina interna para médicos recién graduados}

En el año 2014, el Ministerio de Salud polaco cambió la ley sobre especialidades médicas, para facilitar el camino a los jóvenes médicos ${ }^{3}$. La formación de un especialista en medicina interna requiere de 5 años, fraccionados en un período de 3 y uno de 2 años. Al término del período inicial de 3 años, el médico puede decidir si continúa su formación como internista o cambia la especialidad, por otra de 23 especialidades, sin perder este período inicial.

Durante los 5 años de formación el médico rota por las distintas secciones de medicina interna y debe asistir a cursos comunes para todas las especialidades ${ }^{6}$. Reciben salario por el Ministerio de Salud, o el hospital que los contrata, o la Universidad.

Al final de los 5 años debe rendir y aprobar un examen que consta de una parte oral y otra escrita, con lo cual obtiene el título de "especialista en Medicina Interna" 5 .

La especialidad de medicina interna se puede adquirir por tres vías: la ya descrita, o trabajando como médico residente, o firmando un contrato con un hospital. La mayoría de los médicos escoge trabajar como médico residente, cuyo sueldo es igual en todo el país. En las tres vías de formación de especialistas, los médicos deben rendir y aprobar el mismo examen "PES" que se toma dos veces al año.

Actualmente, muchos médicos jóvenes polacos eligen medicina interna como su especialidad. Esto ocurre porque en Polonia hay escasez de especialistas en medicina interna. Además, el médico puede trabajar en su propia consulta o dispensario.

Maciej Pawlowski, $M D^{1}$, Wlodzimierz Stelmach, $\mathrm{MD}, \mathrm{PhD}^{2}$ ${ }^{1}$ Department of Allergology and Internal Medicine in Children, N. Copernicus Hospital. Lodz, Poland.

${ }^{2}$ Department of Social and Preventive Medicine, Medical University of Lodz. Lodz, Poland. 


\section{Referencias}

1. http://rekrutacja.gumed.edu.pl/1247.html (acceso el 4 de junio de 2015).

2. https://www.cem.edu.pl/ (acceso el 4 de junio de 2015).

3. http://www.mz.gov.pl/system-ochrony-zdrowia/kadra-medyczna-i-ksztalcenie/lekarze-i-lekarze-dentysci/ komunikaty-dla-lekarzy-i-lekarzy-dentystow/liczba-przyznanych-miejsc-rezydenckich-1-31-marca-2015 (acceso el 4 de junio de 2015).

4. https://wors.cmkp.edu.pl/ (acceso el 4 de junio de 2015).

5. http://www.mz.gov.pl/system-ochrony-zdrowia/kadra-medyczna-i-ksztalcenie/lekarze-i-lekarze-dentysci/ komunikaty-dla-lekarzy-i-lekarzy-dentystow/komunikat-dotyczacy-postepowania-kwalifikacyjnego-do-odbywania-modulowych-specjalizacji-lekarskich-i-lekarsko-dentystycznych (acceso el 5 de junio de 2015).

6. http://www.cmkp.edu.pl/ksztalcenie-podyplomowe/ studia-specjalizacyjne-lekarzy/programy-specjalizacji-lekarskich/modulowe-programy-specjalizacji/ (acceso el 5 de junio de 2015).

Correspondencia a:

Maciej Pawlowski, MD.

macpaw3@wp.pl 